\title{
Within the Medieval Perspectival Image: New Methods Old Art
}

\author{
J. Kirk Irwin \\ Birkbeck, University of London \\ 55 East Monroe \#3800 \\ Chicago, IL 60603, USA \\ Jkirkirwin@gmail.com
}

\begin{abstract}
The premise of this paper is that the application of new visualization methods to the study of medieval perspective will reveal features, qualities, characteristics, patterns and typologies that would otherwise not be visible, and that these newly envisioned elements will provide the basis for a new set of questions as to the nature of the medieval spatial construct. Case studies will include an analysis showing the amount of area shown as Heaven and as Earth in Giotto's Arena Chapel compared to the same in the frescos in the Upper Basilica in Assisi. The quantities will be measured using AutoCad and the data will be visualised with scatter plots using Viewshare. Another case study also using AutoCad and Viewshare will show the consistency of lines of sight measured as angles in the same frescos.
\end{abstract}

Digital humanities. Visualisation. Art history. Perspective.

\section{INTRODUCTION}

This paper describes several methodological issues illustrated by case studies that emerge from the application of digital tools to the study of medieval perspective. While the Guidelines for the Evaluation of Digital Scholarship in Art and Architectural History, published in 2016 by the College Art Association and the Society of Architectural Historians, define an appropriate generalized framework within which many of these issues reside, there are other questions specific to art historical inquiry and in particular to the 1300 s that deserve further attention.

1. Digital graphics software is based on a three-dimensional representational system. The third dimension had not been invented yet in the Trecento at least as far as art practice is concerned, although recent scholarship shows that the theoretical basis for the third dimension had been established by the turn of the first millennium centuries prior to the development of linear perspective (Raynaud, Optics 2014). Therefore, the capacity of digital tools to model spatial reconstructions of medieval perspective remains limited to the definition of shape, proportion, ratio and size.
2. Digital platforms produce lines that are thin and on a flat surface while Trecento art does the opposite. Much of the art of the Trecento is executed in fresco, painted with or on to plaster adhered to wall surfaces that are over seven hundred years old. The interface between digital representation and the thick line-work on uneven surfaces typical of Trecento art lead to questions pertaining to dimensional tolerance, acceptable levels of accuracy, and the integrity of original data and images.

\section{NEW METHODS OLD ART}

Modern perspective as most people understand it has its basis in a set of theories dating from the early Renaissance articulated by the Humanist Leon Battista Alberti. In his book, Della Pittura, he describes a method for representing spatial volume on a flat surface. Modern techniques for drawing one-point linear perspective derive from this. Because of its mathematical basis, Alberti's method is easily adaptable to digital formats. Such is not the case for perspective dating from prior to Alberti. With its basis in optical perception rather than mathematics, Medieval perspective presents an entirely different set of challenges. While the capacity within digital tools for three- dimensional 
representation is not applicable to medieval perspective, there are other ways in which digital media may be employed to facilitate its study.

The first way is through the capacity to measure. An example of this is shown in Figure 1. This is a panel from Giotto's Arena Chapel in Padua, the Nativity of Christ. In this narrative one finds the Christ Child in a simple structure, a manger, with Mary and Joseph, an attendant, two bystanders, a ring of angels, and several animals. To the modern eye, Giotto's manger and the people in it and around it may seem out of place, or slightly out of proportion to one another. Yet, within the context of medieval art practice there is nothing out of the ordinary at all with this scene. Digital tools are useful in showing how this is.

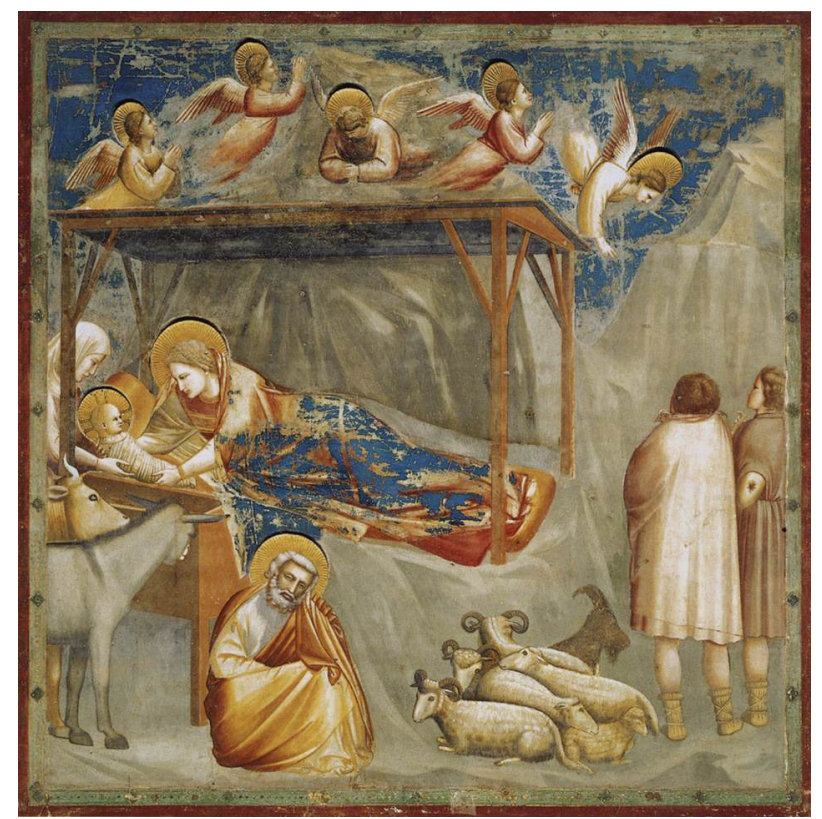

Figure 1: Giotto, Nativity of Christ, Padua, Arena Chapel

Figure 2 shows an overlay of several proportional relationships evident in the Nativity. Because of the precision inherent in the digital technology it is possible to bring to light evidence of Giotto's method that would otherwise remain hidden. Before going further, it is necessary to present a few comments in general about proportion in art. As the Vitruvian proportions have recently taken on rock star status due to a popular book and movie and the image of the Vitruvian Man by Leonardo perhaps enjoys even greater familiarity as it is imprinted on the one Euro coin, one is reminded of what it is that the Vitruvian proportions represent. Vitruvius writing in the late Roman Empire advocated that the ideal human body should be proportioned in a manner that kept all of its parts in specific mathematical relationships. Vitruvius' states that the overall height of a person should be equal to eight head lengths and ten face lengths measured from the forehead to the chin (Vitruvius,
Book III). He also says that buildings should be proportioned in the same manner as the human body if they are to be ideally proportioned.

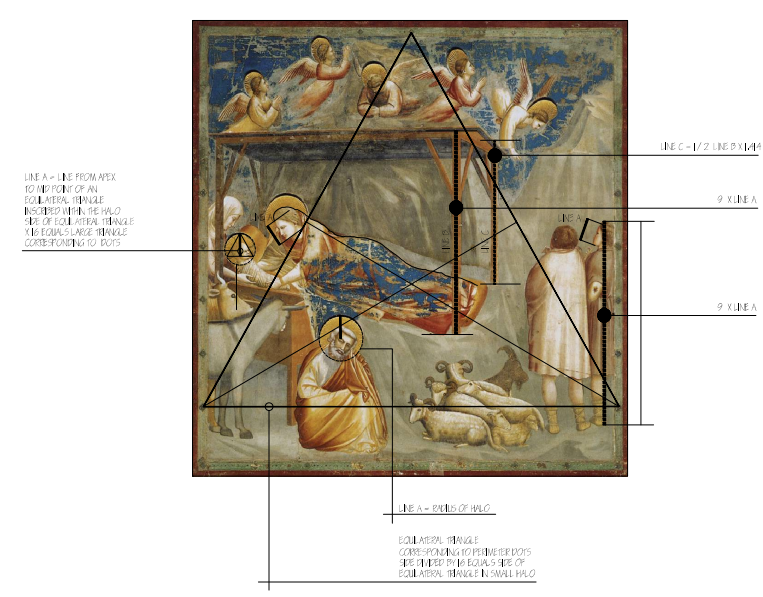

Figure 2: Giotto, Nativity of Christ, Padua, Arena Chapel

There were other proportional systems available to artists in the Middle Ages in addition to Vitruvius. These include the proportions suggested by Cennino Cennini in his Handbook on Art and Dionysus of Fourna who codified Byzantine practice in his Mount Athos Painter's Manual. Cennini suggested a height of eight and two thirds faces and Dionysius suggested a height of nine faces. Dionysius followed Byzantine practice while Cennini's set the standard for medieval practice (Panofsky 1955).

One would expect therefore to find in Giotto's figures Cennini's suggested height of eight and two thirds faces instead of the Byzantine practice of using nine faces as a standard height. Without precise measuring tools, it would not be possible to determine Giotto's proportioning method. Determining a height in proportion to the measurement of a face and doing this within an appropriate degree of dimensional tolerance is possible with good digital images and good graphics software. Using AutoCad and an uncorrupted image one can determine several characteristics unique to the Nativity panel.

First, is that the height of the left bystander is equal to the nearest post holding up the manger. Second, is that this height divided by nine equals the radius of the halo around Joseph's head. Third, is that the unit nine measure equals the long side of a rightangle triangle with sides proportional to one, two, and square root of three, inscribed within the Christ Child's halo. The one/ ninth unit of measure corresponds with the height of the face of the bystander and also the height of the face of Mary.

The second way in which digital tools may facilitate a study of medieval perspective is by assessing 
shape, again turning to Giotto's Arena Chapel as an example, this time to an image of the entire south wall of the chapel. Essential to Giotto's compositional format is the relationship between three types of space: heaven, earth and hell. Individual panels show people, angels, demons and other creatures moving and gesturing from one kind of space to the next. The Nativity scene includes this dynamic quality and is illustrated by the lower right two figures and the right-most angel. There is a sense that they are direct communication with each other. What then are the formal qualities of the relationship between heaven and earth in these panels? How might this dynamic quality be studied using digital tools?

Figure 3 shows a figure ground analysis of the south wall of the Arena Chapel. By making the sky black and eliminating the ground by showing it as a void, an important characteristic emerges. Giotto tended to weave heaven and earth using the colour of the sky as background and using elements of temples, tress, and crenulations at the top of city walls as foreground. Another way in which this relationship may be studied is by looking closely at the line that occurs between heaven and Earth. This is shown in Figure 4. By excluding the foreground and the colour of the sky, a single characteristic emerges that may be studied in isolation. Giotto's horizon line considered as a datum, or line of reference, may now be seen as an element within a larger context, the entire south wall. Had it not been isolated, its role in Giotto's formal planning would have been less noticeable.

While any of this may be replicated graphically using manual drawing techniques, there is one significant advantage to using a digital format; the shapes are all quantifiable. What might quantifiable data say about the nature of Giotto's art in the Arena Chapel? There are two places to check for this. First, is in the amount of area represented as heaven compared to earth, and second, is in any correlations between the various angles used by Giotto to represent depth. Using AutoCad, the areas comprising heaven and earth may be measured and compared. The resulting data showing percentages of heaven to earth indicate that there is no consistent relationship evident in the comparison. The percentage of heaven area compared to earth area is roughly thirty to forty per cent of the panel in the upper register, and gradually reduces to about ten per cent in the lower register. The only pattern that can be determined is that the amount of sky reduces from top to bottom except for the middle panels. The figure ground image shows a general reduction of sky area from top to bottom and a tendency for the sky to move downward toward the centre of the chapel. This would indicate that while Giotto painted his human figures with exact precision the overall compositional effect of heaven and earth, or figure and ground, were not mathematically contrived.

Another example focuses on the angles that Giotto used in representing depth. Each of these is measurable, again using AutoCad to see if certain angles were used in specific parts of Giotto's compositions. Angles that look identical to the eye vary when measured digitally. This particular analysis measured the depth angles and then took note of their placement in either the upper third, middle third, or lower third of each panel. With this data, scatter plots were developed that clarify that while in some instances angles used in the lower portions of the panels were steeper than angles in the upper portion of the panels, a consistent pattern of angles could not be inferred (Figure 5). There is not a consistent pattern of angles across the south wall. The digital media helped to show a set of inconsistencies. What then is the value of this exercise if it did not result in a pattern; that there is an inconsistent use of angles across the south wall as a whole, but a consistent use of angles within individual panels. It is this consistent use of angles within each panel that links architecture to people in Giotto frescos.

In the Arena Chapel cycle, there is a relationship between the angles in each individual panel between angles in receding walls and lines of sight between individuals shown in the narrative scenes. An example of this is the Golden Gate panel (Figure 6). The angle of the receding wall is represented at five degrees. This is precisely the angle between the attending figure standing beside the figure known as the Women in Black and image of Joachim and Anne greeting one another. More precisely, a five-degree angle exists between the mouth of the attending figure and the eyes of Joachim and Anne. A second example is in the Mocking scene where the angle of the left ceiling line is identical to the line of site from Christ to the individual shown kneeling to his left. Figure 7 shows how a line exists from the kneeling individual's eyes to Christ's eyes and that this line matches the line Giotto uses to depict depth. Were it not for digital technology an incorrect determination could have been made because angles would have been identified as identical when they are not, and patterns would have emerged that were erroneous.

That each panel has a unique identifier linking the architectural setting to the lines of sight perhaps speaks to Giotto's workshop method and the extent to which he delegated authority to individual members of his team. Or, assuming that Giotto planned each panel individually prior its being placed on the wall in plaster, it may show that he intentionally made each angle slightly different so that differences in execution would not be 
negatively perceived. These were probably not visual adjustments made in the field as the work was underway because each angle correlates to a specific line of site, and returning to an earlier point, that the placement of the eyes within a face was directly related to the proportional relationships between people and buildings in each panel.

So far this inquiry has focused on Giotto in the Arena Chapel. By comparing the findings at Padua to findings in the Assisi St. Francis cycle further insights emerge as significant differences between the two fresco cycles becomes evident. The Assisi frescos in the Upper Basilica are not directly comparable to those in Padua. They exist in a single register or row. They are much larger that the Padua frescoes and the relationship between the people and the architecture is not proportionally established within the composition. A figure ground study of one part of the Assisi cycle shows how the Assisi Master created a relationship between heaven and earth that differs from what is evident at Padua. It is more diffuse, broken into pieces, and consists of larger line segments. Furthermore, unlike the Padua panels the relationship between people and buildings is not clearly denoted with a consistent use of an angle. The angles of the buildings do not match aligning gestures. The lines of sight are not coordinated with the receding lines of the attendant architecture.

Earlier in this paper the notion of dimensional tolerance was raised as a primary concern for anyone conducting research in a visual medium in the Digital Humanities. Specific to the images used above, the following issues had to be addressed. Giotto's frescos in the Arena Chapel are not square. Some online images have been altered to make them square. Fresco painting is a skill that involves painting with pigmented plaster. When lines are struck in a fresco these may be up to one half inch in width. The difference between a line width on a computer screen and a line width drawn in plaster on a seven-hundred-year-old wall must be taken into consideration during a digital analysis. What appears to be inaccurate on a monitor may very well be within a reasonable degree of accuracy with respect to the methods used in executing the subject work of art. Halos present additional unique challenges. Halos, while almost always rendered accurately as a circle, sometimes also have a surface dimension. Some are sculpted such that the tops project out from the wall surface in a way that creates a gap between the halo and the surrounding surface. This gap is often filled in with colourless plaster. Whether to measure the circumference of a halo from the area that is gilded or from the area of infill plaster is a matter that should be decided on a case by case basis.

This paper has shown that although digital tools have a mathematical basis, there are ways in which these apply to artistic analyses focused on premodern art. Furthermore, when the application of digital tools results in a data set that represents a set of inconsistencies this can be an informative as if the opposite result were achieved. The findings presented here are preliminary in their scope. As new digital tools develop, other methods will develop alongside these. Yet, the tool kit available to researchers at present is quite adequate to make significant advances in art historical study focused on medieval perspective.

\section{REFERENCES}

Alberti, L. B. (1950) Della Pittura. Sansoni, Firenze.

Cennini, C. (1899) The Book of the Art of Cennino Cennini. trans. Christiana J. Herringham. Allen and Unwin, London.

Panofsky, E. (1955) Meaning in the Visual Arts. Doubleday, Garden City, New York.

Raynaud, D. (2014) Optics and the Rise of Perspective: A Study in Network Knowledge Diffusion.

Vitruvius, P. (1960) Vitruvius: The Ten Books on Architecture. Dover, New York.

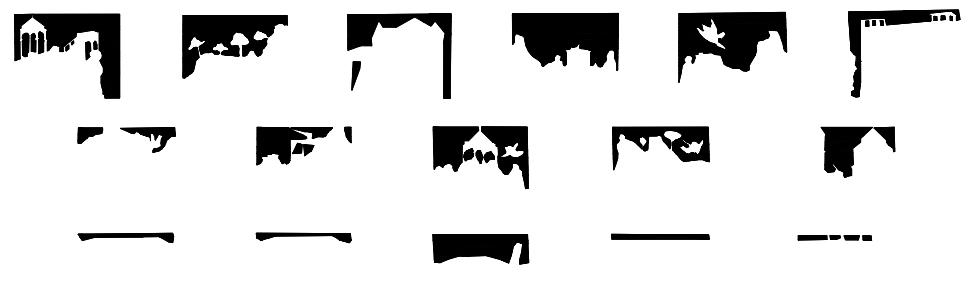

Figure 3: Figure Ground Drawing, South Wall, Padua, Arena Chapel 

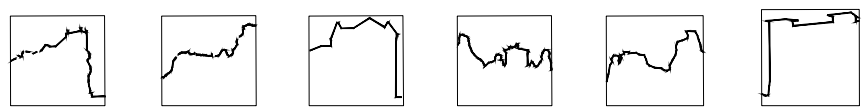

Figure 4: Horizon Diagram, Padua, Arena Chapel

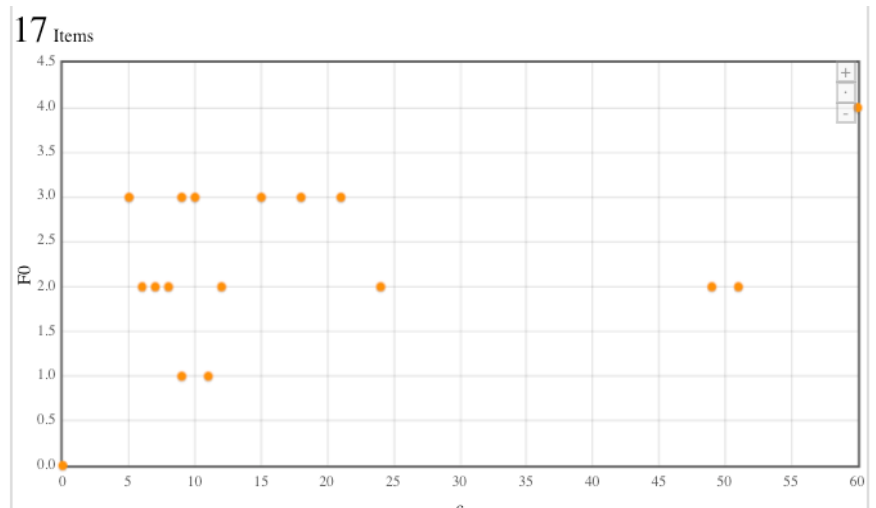

Figure 5: Scatter Plot, Angle distribution, South Wall, Arena Chapel, Padua

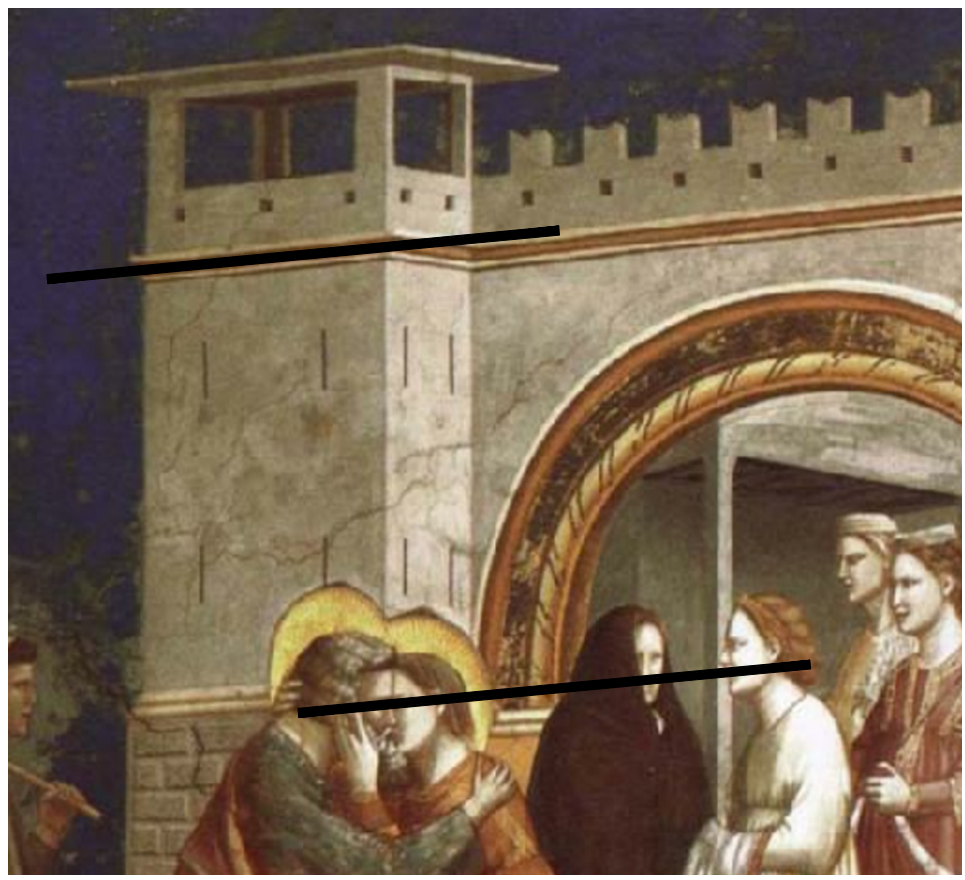

Figure 6: Detail, Padua, Arena Chapel 